Scientiæ studia, São Paulo, v. 8, n. 3, p. 339-66, 2010

\title{
st \\ O método da astronomia segundo Kepler
}

\author{
Claudemir Roque Tossato \& Pablo Rubén Mariconda

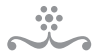

RESUMO

Este artigo trata dos procedimentos metodológicos empregados por Johannes Kepler, particularmente aqueles utilizados no processo de elaboração das duas primeiras leis dos movimentos planetários. É nossa intenção mostrar que a prática astronômica de Kepler liga-se à proposta de hipóteses (físicas e matemáticas) e à valorização da precisão nos dados observacionais com vistas a obter, por meio de procedimentos rigorosos, as regularidades (matematicamente expressáveis) dos movimentos planetários. É só depois que Kepler procura por uma explicação das regularidades descobertas (as leis), fazendo a hipótese da ação magnética exercida pelo Sol, colocado no centro físico do sistema. NaAstronomia nova, ele modifica o estatuto metodológico das hipóteses astronômicas do início do século xviI (Ptolomeu, Copérnico e Brahe), promovendo a passagem da astronomia matemática, descritiva, para a astronomia físico-matemática, explicativa.

PALAVRAS- Chave $\bullet$ Kepler. Hipóteses astronômicas. Leis dos movimentos planetários.

Observação astronômica. Método astronômico.

\section{INTRODUÇÃO}

O papel de Johannes Kepler (1571-163o) para o desenvolvimento da história da astronomia e da cosmologia modernas revela-se em dois aspectos: primeiro, na elaboração das três leis dos movimentos dos planetas, a saber, a lei da forma elíptica, a lei das áreas e a lei harmônica; segundo, em sua defesa contundente do copernicanismo, o que o coloca, juntamente com Galileu, como um dos principais defensores das hipóteses copernicanas de centralidade do Sol e de movimento da Terra. Contudo, embora se reconheça a importância de Kepler para a constituição da astronomia, os aspectos ligados a sua metodologia são deixados frequentemente em segundo plano.

A astronomia de Kepler insere-se no âmbito do copernicanismo, não somente pela admissão das hipóteses centrais da proposta copernicana, a saber, a de centralidade do Sol e a de mobilidade da Terra, mas, sobretudo, pelos desenvolvimentos internos que ele forneceu para a proposta original de Copérnico. Desses desenvolvimentos, Kepler estipulou uma nova maneira de fazer a astronomia, isto é, um novo método para 


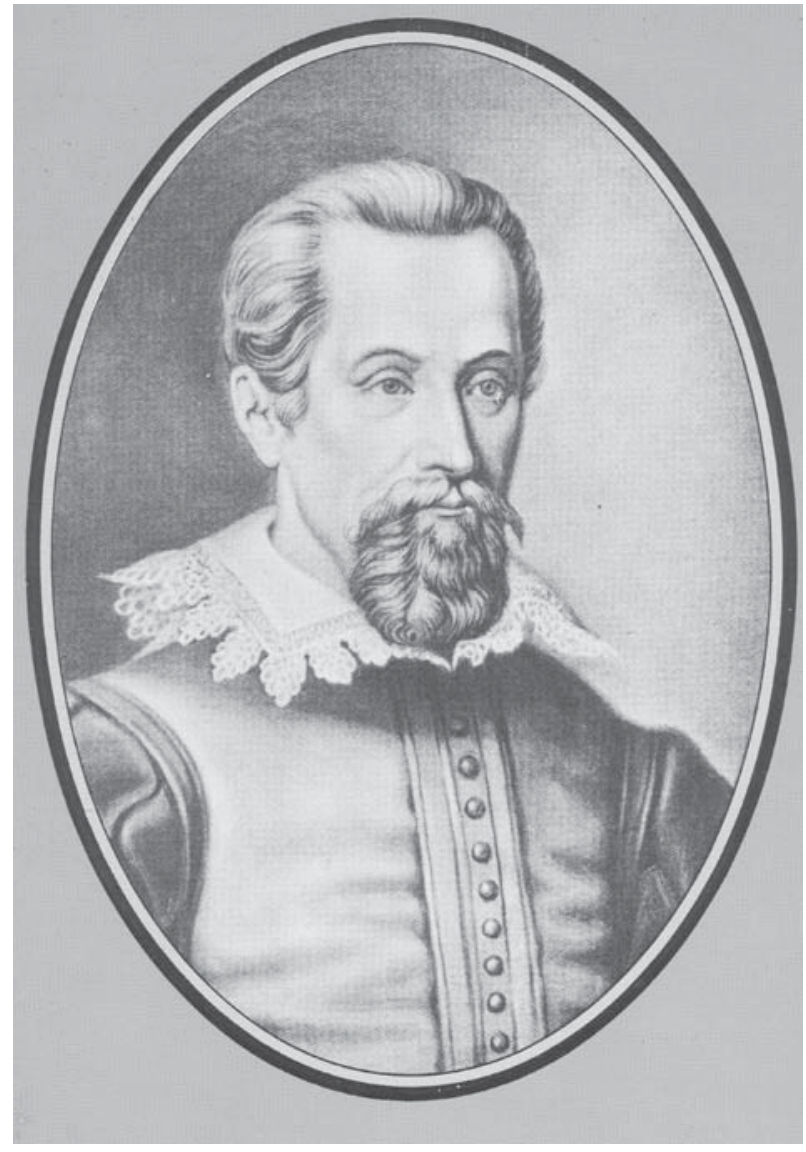

Figura 1. Johannes Kepler (1571-1630), fundador da astronomia moderna. Deve-se a ele as três leis dos movimentos planetários e a elaboração de uma nova metodologia para a astronomia científica.

tratar os problemas acerca dos movimentos planetários. É dessa nova maneira de Kepler fazer astronomia que trataremos neste texto.

O nosso objetivo é apresentar os aspectos metodológicos envolvidos no processo pelo qual Kepler elabora as duas primeiras leis dos movimentos planetários - a lei da forma elíptica da trajetória planetária e a lei das áreas. Restringimonos às duas primeiras leis, excluindo a terceira - a lei harmônica - por que elas expressam as condições que conduziram ao abandono do padrão de inteligibilidade dado pelo axioma platônico de que os movimentos são circulares e uniformes. Nossa intenção é, sobretudo, a de entender o processo de construção das duas primeiras leis e de como elas representaram uma modificação no estatuto epistemológico e metodológico da astronomia do início do século xviı, especificamente quanto ao uso do conceito de "hipótese astronômica". Para tanto, trataremos inicialmente do processo de obtenção das duas primeiras leis dos movimentos planetários, destacando os seus pontos mais relevantes; em seguida, discutiremos o método kepleriano para a astronomia.

\section{A Astronomia nova e A ESTRATÉGIA METOdológICA DE KEPLER}

Escrever sobre a metodologia kepleriana é arriscar-se profundamente ao erro e ao engano. Isto se explica, fundamentalmente, pela dificuldade de tal trabalho. Excetuando-se a obra Apologia de Tycho, que versa sobre o estatuto epistemológico do uso de hipóteses na astronomia, e algumas passagens isoladas de suas obras, nas quais Kepler apresenta algumas etapas de seu procedimento, Kepler pouco escreveu diretamente acerca das questões metodológicas. Em particular, nada escreveu sobre como obteve 
as suas leis dos movimentos planetários ou de suas conquistas na óptica. Tudo que escreveu em astronomia e óptica corresponde a extensos relatos de suas descobertas importantes nesses domínios. O que ele apresenta ao leitor de suas obras é todo o processo, todas as etapas que percorreu para obter os seus resultados, mas sem refletir sobre o procedimento (o método) que o guiava. Por exemplo, em sua principal obra astronômica, Astronomia nova, onde são formuladas as duas primeiras leis dos movimentos planetários, Kepler apresenta seu percurso por meio de um relato mostrando erros e acertos, sem derivar qualquer regra metodológica. Assim, não temos em Kepler uma discussão preliminar tal como fizeram Descartes e Bacon, para apresentar como pretendiam construir o conhecimento científico, para explicitar as regras admitidas que devem acompanhar toda empreitada de obtenção do conhecimento. Kepler, diferentemente, apresenta um extenso relato de todas as etapas que o conduziram à descoberta das duas primeiras leis dos movimentos planetários e é nessa extensa descrição que se deve encontrar o que serviu de guia a Kepler.

Podemos, seguindo a própria descrição de Kepler, reconstruir o caminho empreendido, objetivando extrair as regras metodológicas subjacentes para o caso das duas primeiras leis ao relato contido na Astronomia nova. ${ }^{\mathbf{1}}$

A obra Astronomia nova, de Kepler, é escrita com o propósito de mostrar que não há equivalência entre as hipóteses, na medida em que as hipóteses copernicanas da centralidade do Sol e do movimento da Terra estão melhor adequadas às aparências, pois explicam por que essas aparências se dão, e não são meramente representativas dos fenômenos tomados em si. Em outras palavras, as hipóteses astronômicas eram entendidas na época de Kepler como pertencentes à astronomia descritiva, na qual as hipóteses são matemáticas, pois servem somente para o cálculo das posições dos planetas. Kepler modifica esse estatuto das hipóteses e as trata como pertencentes à astronomia explicativa, entendidas, agora, como hipóteses físico-matemáticas. O que Kepler exige da astronomia é que o caráter explicativo torne-se parte integrante da teoria dos movimentos planetários, pois as explicações sobre os aspectos físicos dos movimentos planetários é um requisito da posição copernicana.

A Astronomia nova de Kepler é composta de uma introdução e de cinco partes. A introdução trata de dois assuntos. O primeiro é sobre os objetivos da obra e a apre-

1 O leitor interessado no processo de elaboração das duas primeiras leis de Kepler poderá consultar, principalmente, Small (1963), que representa umas das primeiras tentativas de reconstrução do itinerário kepleriano; Caspar (1959), Dreyer (1953), Koyré (1961) e Simon (1979) são clássicos, que muito influenciaram na compreensão do pensamento de Kepler no século xx; destacam-se também os diversos trabalhos de Aiton (1969, 1975, 1978) e de Wilson $(1968,1972,1975)$ que, com riqueza de detalhes, mostram-nos os aspectos técnicos envolvidos na elaboração da primeira e da segunda leis; recentemente, temos os trabalhos de Stephenson (1987), Martens (2000) e Voelkel (2001) e estes são somente alguns dos comentadores que tratam dessa questão. 
ASTRONOMIA NOVA A I T IO $\Lambda$ O H TO $\Sigma$, S E V

PHYSICA COELESTIS, tradita commentariis

DE MOTIBVS STELLA M $\mathrm{A} R \mathrm{R} I \mathrm{~S}$, Ex obfervationibus G. V.

T $\mathrm{CHONIS}$ B RAHE:

juflu \& fumptibus

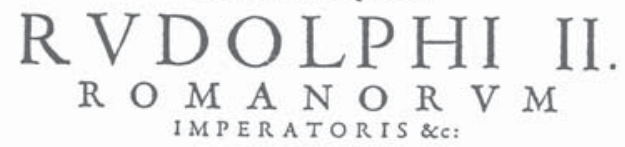

\footnotetext{
Plurium annorum pertinaci ftudio elaborata Pragx,

at S. C. Or.w s. exathematico

JOANNE KEPLERO,

Cum gusdem C. NT:" privikgio peciati

AnNo zrx Dionyfianx clo lo c $t x$.
}

Figura 2. Frontispício da Astronomia nova, de 1609. Nesta obra, pela primeira vez na história da astronomia, o axioma platônico de circularidade e uniformidade dos movimentos dos planetas é negado, o que abre o caminho para a determinação das duas primeiras leis.

sentação de alguns procedimentos - que podemos entender como metodológicos - utilizados por Kepler para dar conta dos problemas envolvidos na determinação dos movimentos planetários. O segundo assunto é uma pequena teoria da gravidade e das marés, assunto que não trataremos neste artigo.

O objetivo de Kepler com a Astronomia nova é "o de reformular a teoria astronômica (especialmente para o movimento de Marte) em todas as suas três formas de hipóteses [ptolomaica, copernicana e brahiana], de modo que se possa construir tabelas que correspondam aos fenômenos celestes" (Kepler, 1937 [1609], p. 20). Ou seja, temos uma preocupação prática, a necessidade de tabe-

las mais confiáveis e, para obtê-las, investigar qual das hipóteses astronômicas é adequada para tanto. Mas o texto continua e lemos:

Eu inquiro sobre as causas físicas e naturais dos movimentos (dos planetas). O resultado eventual dessas considerações é a formulação de argumentos claros que mostram que a opinião de Copérnico sobre o mundo (sofrendo pequenas alterações) é a verdadeira, e que as outras duas são falsas (p. 20).

Para Kepler, o copernicanismo é o verdadeiro modelo de universo, e as razões disso são de ordem física. ${ }^{2}$ Aqui temos a exposição de que Kepler não trata a astrono-

2 Já no Mysterium cosmographicum de 1596, Kepler defendia o copernicanismo dando vários argumentos a seu favor, como, por exemplo, "Minha confiança foi primeiramente estabelecida pela magnífica concordância de tudo que é observado nos céus com a teoria de Copérnico; visto que ela não apenas derivou movimentos passados (...), mas 
mia somente como descritiva, aceitando a equivalência das três hipóteses, mas que a consideração das "causas físicas e naturais dos movimentos" conduzem-no à verdade da hipótese de Copérnico. Isto posto, Kepler explicita a hipótese da centralidade física do Sol:

Ora, o primeiro passo em direção à determinação das causas físicas [dos movimentos dos planetas] está em demonstrar que os planos de todos os excêntricos somente podem intersectar-se no centro do corpo solar (e não em algum ponto aproximado), contrário ao que pensavam Copérnico e Brahe (p. 20).

Para Kepler, essa é uma nova maneira de tratar a astronomia, que mostra sua independência com relação aos dois autores que mais o influenciaram, Copérnico, de quem toma o modelo cosmológico, e Brahe, de quem utiliza os dados observacionais sobre Marte. Pode parecer estranha a referência a Copérnico, mas o cônego polonês não posicionava o centro dos movimentos no corpo do Sol, mas nas proximidades e fez isso em vista do respeito ao axioma platônico de movimentos circulares e uniformes. Kepler é que irá, como veremos mais à frente, retirar a primazia do axioma platônico, transformando-o em uma hipótese, que deve ser testada por sua correspondência com as observações.

Kepler tem consciência da novidade que propõe para a astronomia; daí o sentido do título da obra Astronomia nova, uma nova astronomia, ou seja, uma astronomia praticada com um novo método que visa a determinação da verdade das hipóteses; portanto, visa a obtenção de explicações.

Kepler inicia a primeira parte da Astronomia nova escrevendo sobre os problemas da astronomia de sua época, em particular dos movimentos dos planetas; os principais são duas irregularidades (desigualdades) que notamos quando observamos os movimentos planetários ao longo do zodíaco - a não-uniformidade entre arcos e tempos (primeira desigualdade), e a retrogradação (segunda desigualdade) (cf. Kepler, 1937 [1609], cap. 1). A seguir, Kepler apresenta os três modelos cosmológicos desse período, o ptolomaico, no qual a Terra está no centro dos movimentos e o Sol gira ao seu redor; o copernicano, a Terra é um planeta como outro qualquer e gira ao redor do Sol; e o brahiano, um modelo misto, em que a Terra é o centro do sistema e a Lua e o Sol giram ao seu redor, enquanto que os outros planetas giram ao redor do Sol. Kepler ar-

também previu movimentos futuros (...). Entretanto, o que é mais importante é que daquilo que os outros nos ensinaram como sendo milagre, apenas Copérnico deu-nos a explicação." (Kepler, 1938 [1596], p. 14-5). Porém, deve-se ressaltar que em 1596 Kepler não dispunha dos dados de Brahe, a quem só conhecerá pessoalmente em 1600. Os dados de Brahe, os mais precisos até então, permitirão a Kepler, na obra de 1609, defender o copernicanismo de modo muito mais contundente. 
gumenta que eles são equivalentes sob o ponto de vista da determinação dos posicionamentos planetários, isto é, todos eles conseguem, utilizando artifícios distintos (Copérnico e Brahe usam o concêntrico com epiciclos, ${ }^{3}$ enquanto Ptolomeu utiliza o equante), obter dados relativamente satisfatórios para a determinação dos posicionamentos planetários. Porém, todos eles pecam por não tratar a astronomia sob o ponto de vista físico (cf. Kepler 1937 [1609], caps. 2-6).

Contudo, a primeira parte do livro somente apresenta o problema. A estratégia de Kepler, no restante da obra, será mostrar que, se os modelos em questão são equivalentes sob o ponto de vista descritivo matemático, apenas o copernicano, que sofrerá algumas alterações (o deslocamento do centro matemático para o centro físico), explica as irregularidades dos movimentos dos planetas, o que Ptolomeu e Brahe não conseguem explicar. Apenas o heliocentrismo é que permitirá uma aplicação metodológica explicativa, físico-matemática.

A quinta parte trata das latitudes, na qual Kepler comenta algumas observações dos astrônomos antigos acerca dos movimentos dos planetas, relacionando a essas os resultados a que chegou nas outras partes da Astronomia nova. A seguir, trataremos da segunda, terceira e quarta partes da Astronomia nova, que contêm a formulação das duas primeiras leis dos movimentos planetários, na tentativa de compreender o novo procedimento adotado por Kepler para a astronomia.

\section{O PROGESSO DE ELABORAÇÃO DAS DUAS PRIMEIRAS LEIS}

Levando em conta o relato contido nas três partes que tratam da descoberta da primeira e da segunda leis, Kepler realiza o seguinte itinerário:

(I) trata a astronomia à "maneira dos antigos", isto é, sem tratar das causas físicas dos movimentos, considerando as hipóteses sob o ponto de vista instrumentalista (que está na segunda parte da obra, Astronomia nova, caps. 7 a 21).

(II) modifica o seu enfoque, assume a hipótese compernicana, e considera as causas físicas, chegando à segunda lei (na terceira parte da obra, caps. 22 a 40 ).

(III) elabora hipóteses intermediárias para chegar à determinação da forma da órbita, que demonstra ser a elíptica (na quarta parte da obra, caps. $41-60)$. 


\subsection{A HipóteSE VICÁRIA}

Kepler adota inicialmente uma postura, como ele próprio diz, "semelhante aos antigos" (Kepler, 1937 [1609], cap. 16), ou seja, aceita incontestavelmente o axioma platônico de que os movimentos planetários são circulares e uniformes ou compostos de movimentos circulares e uniformes, considerando que é suficiente a adequação da representação geométrica desses movimentos dos planetas. A hipótese é tomada, assim, como mera hipótese matemática, sem a consideração de causas físicas. A perspectiva é, assim, explicitamente descritiva. Essa etapa é marcada pela utilização da hipótese vicária, também chamada de "hipótese suplementar", entendida como um recurso cinemático, sem qualquer consideração da ação física do Sol. O objetivo da investigação é a de conjugar as observações de Brahe com a descrição correta da forma orbital do planeta Marte, tal como entendido pela hipótese matemática copernicana; para tanto, é necessário admitir que:

(1) é o corpo do Sol que está no centro, aderindo assim ao copernicanismo;

(2) as órbitas são circulares e uniformes, assumindo, dessa forma, o axioma platônico.

Para descrever a órbita do planeta Marte, Kepler tinha que encontrar os seguintes elementos:

(a) a posição da linha das apsides (que passa pelos pontos em que Marte está mais afastado e mais próximo do Sol);

(b) o valor da excentricidade;

(c) a anomalia mediana para qualquer posição de Marte em seu trajeto ao redor do Sol.

O primeiro passo de Kepler consiste na elaboração da hipótese vicária ${ }^{4}$ (cf. Kepler, 1937 [1609], caps. 16-21). Uma das marcas fundamentais da hipótese vicária era assumir o ponto equante ptolomaico para adequar as irregularidades (as trajetórias excêntricas e as diferenças de velocidades) ao axioma platônico. Em suma, a hipótese vicária representa os movimentos irregulares do planeta Marte a partir do equante ptolomaico, um ponto matemático fictício utilizado para determinar os valores da ano-

4 O significado da palavra "vicária" é aquele que faz as vezes de outrem ou de outra coisa. Por essa significação, pode-se entender que a hipótese vicária faz-se passar por outra, isto é, pela hipótese física, a segunda lei dos movimentos planetários. 
malia mediana (tempo) e as posições em que o planeta está mais afastado e mais próximo do equante; o que permite finalmente saber qual é a taxa pela qual o equante se afasta do centro, sendo essa taxa entendida como o valor da excentricidade.

Assumida a hipótese vicária, Kepler toma, então, quatro oposições de Marte catalogadas por Brahe 5 nos anos de 1587, 1591, 1593 e 1595, obtendo triangulações entre cada uma dessas oposições com o centro. O resultado final de Kepler foi que o valor da excentricidade não era fixo, isto é, variava ao longo do trajeto do planeta. Mais tarde, quando Kepler chegar à forma elíptica, abandonará a hipótese vicária. A demonstração de Kepler pode ser sinteticamente apresentada por meio de uma figura, na qual D, G, F e E são as quatro oposições do planeta Marte; B é o centro do excêntrico BG; C é o equante; Aé o Sol; HI a linha das apsides. $\mathrm{O}$ problema de Kepler era o de posicionar as oposições de Marte (D, E, F e G) sobre o excêntrico BG, de forma que B, $\mathrm{C}$ e A estejam posicionadas sobre a linha das apsides de uma maneira tal que os valores (das excentricidades) sejam constantes e, consequentemente, possibilitem a computação dos ângulos HCF e HAF (anomalia mediana e verdadeira, res-

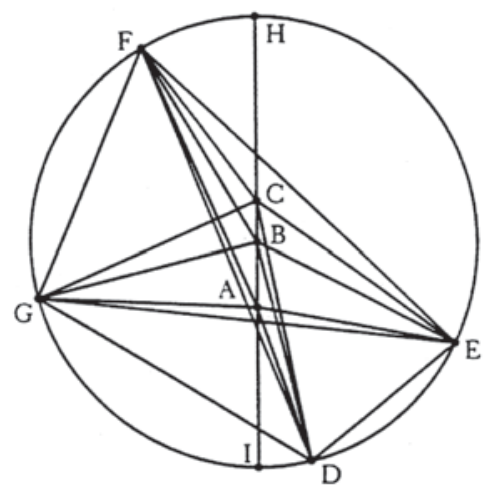
pectivamente) para qualquer posição de Marte. Em outras palavras, para determinar qualquer posição de Marte sobre o zodíaco, era necessário encontrar um valor fixo para a excentricidade - para, dessa maneira, elaborar tabelas sobre os posicionamentos do planeta. Para tanto, Kepler precisou ajustar as quatro oposições de Marte, de modo que $\mathrm{AB}$ fosse igual a $\mathrm{BC}$; isso foi dado através do ajustamento das oposições - uma por vez para, em seguida, relacionar todas com todas. Kepler foi obrigado a fazer várias tentativas, do tipo ensaio e erro, aproximando os dados e tentando construir esse excêntrico. Por exemplo, no ponto F, o ângulo FAH, anomalia verdadeira, é dado pelas observações de Brahe e, dessa forma, o ângulo FCH também o é. Assim, a partir de F pode-se localizar $\mathrm{C}$ na linha das apsides, de uma forma provisória. Após isso, deve-se localizar os outros pontos (G, D e E) de maneira que a posição de C seja igual para todos; isto é, CB tenha o mesmo valor em relação a cada oposição; após isso, BA também tem que ter o mesmo valor de $\mathrm{C}(\mathrm{CB}=\mathrm{BA})$. Kepler obteve os resultados finais de que a longitude no afélio é de $28^{\circ} 48^{\prime} 55^{\prime \prime}$ de Leão; com o valor de $\mathrm{BA}=11332$, e $\mathrm{CB}=7232$, sendo o raio avaliado como igual a 100.000 (cf. Tossato, 1997, p. 63-4).

5 Brahe foi extremamente importante para Kepler. Ele não só forneceu dados mais precisos, sem os quais dificilmente Kepler chegaria às duas primeiras leis, como deixou clara, por contraste, a concepção de método que estipula o conhecimento pelos efeitos e não pelas causas (cf. Tossato, 2004). 
Tendo obtido essas relações, Kepler investiga se o centro do círculo excêntrico liga-se ou não à linha $\mathrm{AB}$, mas, para que isso ocorra, deve-se alterar ou assumir outra direção de HI e dos ângulos HBF e HAF.

Com a hipótese vicária, na linha das apsides, a margem de erro chegou à casa de 2' de arco; contudo, nos octantes $\left(135^{\circ}\right.$ e $\left.225^{\circ}\right)$, chegava a 8 ' de arco. Mas Kepler não aceita o erro de 8', procurando, após a aplicação da hipótese vicária, uma expressão mais satisfatória.

\subsection{A LeI DAS DistÂNGIAS}

Após tratar da hipótese vicária, Kepler mostra que os movimentos da Terra, tal como nos outros planetas, também têm uma excentricidade sem um valor fixo; excentricidade que fica estabelecida para o conjunto dos planetas (cf. Kepler, ${ }_{19}{ }_{7}$ [1609], caps. 22-27). Passa, então, para as suas especulações dinâmicas, que lhe permitiram chegar à lei das distâncias. A formulação dessa lei encontra-se no capítulo 33 da Astronomia nova. A lei expressa que as velocidades são proporcionais às distâncias do planeta ao Sol. Contudo, essa lei só se apresenta como válida na linha das apsides, onde se tem a distância mínima do planeta (periélio), e a distância máxima (afélio) ao Sol; nas longitudes, contudo, ela se mostra inadequada.

Kepler assume, então, o equante ptolomaico como demonstração de que as velocidades dos planetas são proporcionais a suas distâncias ao centro, que é computado pelas uniformidades dos planetas, isto é, o equante ptolomaico determina a proporcionalidade entre as distâncias e os tempos dele ao planeta. Kepler passa a transferir essa relação do equante ptolomaico para o Sol, enquanto centro físico dos movimentos. Algo importante é que Kepler, quando utiliza o equante, bissecta a excentricidade, isto é, posiciona na linha das apsides dois centros, que são, na verdade, dois focos: um é o centro físico (que, como Kepler é copernicano, representa o corpo físico do Sol), o outro, um centro matemático. Seu raciocínio pode ser compreendido com o auxílio da seguinte figura:

Ora, eu próprio afirmo que $v \chi$, assim designada como o arco de tempo (como apontou Ptolomeu) está para o arco $\delta \psi$, o qual o planeta percorre, aproximadamente como $\alpha \delta$, a distância

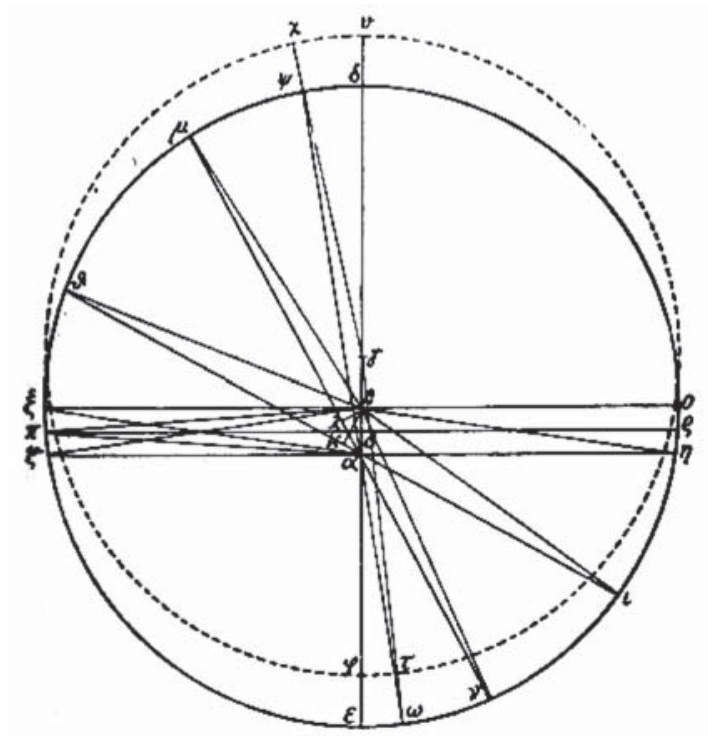


do arco $\delta \psi$ a partir do centro do mundo, está para $\delta \beta$, a distância mediana dos pontos $\pi$ e $\rho$ a partir de $\alpha$. E, igualmente, o arco de tempo $\phi \tau$ está para o arco do movimento do planeta $\varepsilon \omega$, aproximadamente como $\alpha \varepsilon$, a distância do arco $\varepsilon \omega$ a partir do centro do mundo $\alpha$, está para $\varepsilon \beta$ e $\alpha \pi$, a distância mediana do centro do mundo, a qual pode ser encontrada pelos pontos $\pi$ e $\rho$ (Kepler, 1937 [1609], p. 234 ).

A figura mostra basicamente o movimento real do planeta (caso o percurso seja circular), representado pelo círculo contínuo, e o movimento excêntrico, dado pela circunferência tracejada; $\alpha$ representa o centro do mundo, isto é, o centro físico dos movimentos; $\gamma$ é o equante, o ponto fictício que determina os arcos de tempo $\chi v$ e $\varphi \tau$ como iguais, isto é, esses arcos são uniformes, pois seus tempos de percurso são idênticos.

Kepler demonstra, mediante a teoria geral da proporcionalidade, que os arcos de tempos obtidos pelo equante $-\chi v$ no afélio (ou apogeu) e $\varphi \tau$ no periélio (ou perigeu) - são proporcionais aos arcos das distâncias computadas a partir do centro físico dos movimentos, $\psi \delta$ no afélio e $\varepsilon \omega$ no periélio; e isso ocorre em razão da relação entre a excentricidade dada pelo centro do mundo e o centro físico (lembrando que a excentricidade foi bissectada), $\alpha \beta$. Assim, a relação seria:

$\checkmark \chi: \delta \psi:: \alpha \delta: \delta \beta$, para as posições no afélio; e $\phi \tau: \varepsilon \omega:: \alpha \varepsilon: \varepsilon \beta$, no periélio.

Essa proporcionalidade indica que o planeta percorre arcos de tempos desiguais conforme ele esteja mais próximo ou mais afastado do centro físico dos movimentos. Kepler infere, a partir dessa relação (e por uma série de cálculos que não vem ao caso nos remetermos a eles) que essa oscilação de tempo se dá pela ação do centro físico $\alpha$ nos arcos de tempo, considerando que essa ação é determinada pela distância do planeta ao centro dos movimentos. Entretanto, Kepler generaliza erroneamente essa relação entre o centro físico com o afélio e o periélio para todas as distâncias orbitais do planeta, formulando a lei que ficou conhecida como lei das distâncias, expressa, segundo Kepler, como “(...) que a rapidez no periélio e a lentidão no afélio são proporcionais, o mais que possível, às linhas unidas do centro do mundo ao planeta" (Kepler, 1937 [1609], p. 233-4).

Em outras palavras, as várias distâncias entre o planeta e o centro físico dos movimentos fazem o planeta perder ou ganhar velocidade, diminuindo ou aumentando o tempo de percurso dos arcos de tempo (entendendo-se esses arcos de tempo como o trajeto de uma posição a outra, que podem ser computadas mediante o cálculo entre as anomalias medianas e verdadeiras e a equação ótica). 
Assim, Kepler utiliza o equante ptolomaico para obter as relações entre os tempos de percurso; após isso, transfere o problema para o centro físico dos movimentos, que é o que de fato interessa na procura de explicar os deslocamentos desiguais dos arcos percorridos pelos planetas em seus movimentos. Para explicar essa relação entre tempos e distâncias, Kepler postula o seu conceito de força, iniciando a pesquisa acerca da causa física que gera o comportamento irregular dos planetas.

\subsection{A Hipótese DAS SUPERFÍ́cIES}

O próximo passo dado por Kepler consiste na admissão da hipótese das superfícies, a qual se constitui na segunda lei dos movimentos planetários. ${ }^{6}$ Tal hipótese admite a proporcionalidade entre as áreas e os tempos percorridos durante o trajeto de um planeta ao redor do Sol. Na formulação da hipótese das superfícies, Kepler substitui o ângulo formado pela anomalia mediana por uma área percorrida em um certo tempo. Seu procedimento é basicamente o seguinte:

$\mathrm{Na}$ figura, seja A o Sol, B o centro da órbita, CD a linha das apsides, $\mathrm{G}$ a posição de Marte após a sua passagem por C (afélio). O ângulo CBG é a anomalia excêntrica; o ângulo CAG é a anomalia verdadeira; e à diferença entre esses ângulos, que é o ângulo BGA, Kepler chama de equação ótica.

Tendo esses elementos, Kepler precisava encontrar a equação excêntrica (que seria, dada a aceitação da circularidade do axioma platônico, a equação que determinaria o valor da excentricidade para a descrição de uma órbita circular), que é a diferen-

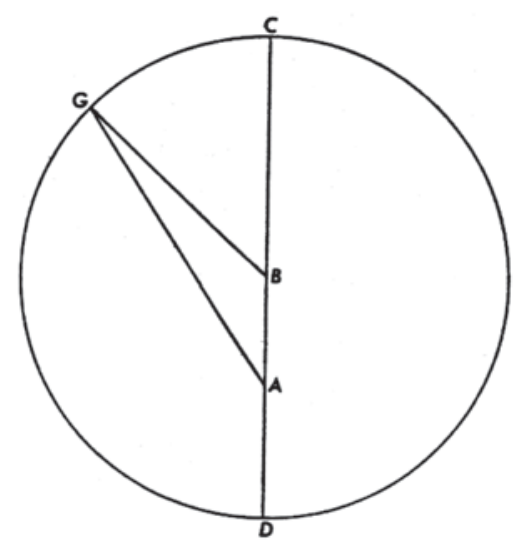
ça entre a anomalia mediana e a verdadeira.

Para encontrar a anomalia mediana, Kepler utiliza a hipótese da superfície. A área CAG é medida em graus, sendo que esses graus dariam o tempo gasto pelo planeta para cruzar o arco CG. Com qualquer ângulo conhecido após a passagem do planeta pelo afélio, por exemplo, o ângulo da anomalia excêntrica CBG, e conhecendo-se o valor da excentricidade $A B$, pode-se, pela hipótese das superfícies, saber o valor do tempo em graus da área ABG (área que Kepler denomina de equação física), obtendo, assim, o valor da anomalia mediana. Para determinar a anomalia verdadeira, basta sub-

6 A hipótese das superfícies tem uma história particular. Inicialmente, Kepler a calcula respeitando o axioma platônico, o que gera desvios apreciáveis; porém, quando ela é aplicada à forma elíptica, isto é, quando Kepler obtém, após a segunda lei, a primeira lei, esses desvios desaparecem. 
trair trigonometricamente o ângulo CBG do ângulo BGA. Na utilização da hipótese das superfícies, Kepler altera o procedimento ptolomaico, objetivando encontrar a anomalia mediana na forma de áreas percorridas, computadas como o tempo de percurso dessa área, enquanto que na formulação ptolomaica, era considerado o tempo do arco, e não da área. Conhecendo-se a anomalia mediana e a anomalia verdadeira, poder-seia encontrar a equação excêntrica, determinando o valor em que a excentricidade seria constante na órbita circular.

Assim, os cálculos empreendidos por Kepler na elaboração da sua hipótese das superfícies foram obtidos em função da conjugação dos valores da anomalia mediana a partir do centro físico dos movimentos para, em seguida, relacioná-los às distâncias percorridas pelo planeta no trajeto correspondente a essa anomalia. Dessas pesquisas, Kepler obteve como resultado final que os raios vetores, que unem o planeta ao Sol, percorrem áreas iguais em tempos iguais, que é o que afirma a segunda lei dos movimentos planetários. Cabe notar que, para chegar à formulação da lei das áreas, Kepler modifica o tratamento tradicional de obtenção da anomalia mediana. Em Ptolomeu, a anomalia mediana era computada a partir do equante, tomado a partir de um ponto fictício; na formulação kepleriana, entretanto, essa anomalia é calculada por um equante tomado no centro físico dos movimentos, que no caso é o Sol.

Após esse raciocínio, Kepler procura uma demonstração geométrica para a forma circular da órbita por meio de uma decomposição em áreas (superfícies). Divide a circunferência em triângulos, tentando equacionar as distâncias das linhas extremas desses triângulos. Vejamos com detalhe como procede Kepler:

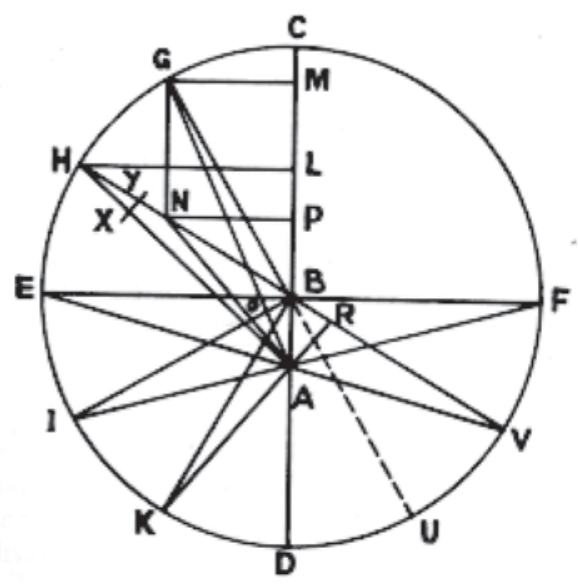

Seja AB a linha das apsides, A o Sol (ou a Terra para Ptolomeu); B o centro do excêntrico $\mathrm{CD}$; todo o semicírculo $\mathrm{CD}$ deve ser dividido em qualquer número de partes iguais, CG, GH, HE, EI, IK, KD, e sejam os pontos A e B conectados com os pontos de divisão. Portanto, AC é a distância maior, enquanto que $\mathrm{AD}$ é a distância menor, e as outras, em ordem, são AG, AH, AE, AI, AK. Evisto que os triângulos sobre alturas iguais estão entre si como as suas bases, ${ }^{7}$ os setores, ou triângulos, CBG, GBH e assim todos

7 "Os triângulos e paralelogramos, que têm a mesma altura, estão entre si como suas bases" (Euclides, 1956, v. 2, p. 191, Livro 6, proposição 1). 
têm a mesma altura, os lados iguais BC, BG, BH, eles são, portanto, todos iguais. Mas todos os triângulos estão contidos na área CDE, e todos os arcos ou bases estão contidos na circunferência CED. Portanto, por composição, ${ }^{\mathbf{8}}$ como a área CDE está para o arco CED, assim a área CBG está para o arco CG, e, alternando, 9 como o arco CED está para CG, CH e o resto pela ordem, assim, está a área CDE para as áreas CBG, CBH e o restante pela ordem. Portanto, nenhum erro é introduzido se as áreas forem tomadas pelos arcos desse modo, substituindo as áreas CGB, CHB pelos ângulos da anomalia excêntrica CBG, CBH (Kepler, 1937 [16o9], p. 264).

Na passagem acima, Kepler apresenta inicialmente os dados do problema. Em AB, a linha das apsides, A é o Sol, B o centro excêntrico. Divide, em seguida, o semicírculo CD em partes iguais, unindo cada ponto ao centro B e ao Sol A, formando vários triângulos. Aplica a esses triângulos a teoria da proporcionalidade dos Elementos de Euclides, estabelecendo proporções entre os arcos e as áreas computadas a partir do centro, B, do excêntrico; dessa maneira, temos:

(1) Os triângulos GBG, GBH, e os demais, têm a mesma altura; assim, pela proposição 6 do livro 1 dos Elementos de Euclides, temos que os lados BC, BG, BH e os demais são todos iguais;

(2) Como todos os triângulos estão contidos na área CDE e todos os arcos ou bases estão contidos na circunferência GED, portanto, pela definição 14, do livro 5 dos Elementos, temos que: área CDE: arco CED:: área CBG: arco CG;

(3) E, alternando, pela definição 12 do livro 5 dos Elementos: arco CED: arcos CG, CH e os demais:: área CDE: áreas CBG, $\mathrm{CBH}$ e as demais (as áreas vão se acumulando).

Até aqui, Kepler associou as áreas com os arcos (ângulos) da anomalia excêntrica. Em seguida, Kepler estabelece a proporção entre as áreas percorridas a partir do centro do excêntrico e as áreas percorridas a partir do centro físico, utilizando para isso as semelhanças dos triângulos construídos; demonstra que todos esses triângulos

8 "Composição de uma razão significa tomar o antecedente juntamente com o consequente como um em relação ao consequente em si mesmo" (Euclides, 1956, v. 2, p. 134-5, Livro 5, definição 14).

9 "Razão alternada significa tomar o antecedente com relação ao antecedente e o consequente com relação ao consequente" (Euclides, 1956, v. 2, p. 132, Livro, definição 12). Aplica-se a definição 12 na proposição 16, do mesmo livro: "Se quatro magnitudes forem proporcionais, também serão proporcionais alternadamente" (p. 164,-5). 
estão sobre a mesma área, o que possibilita reunir todas as distâncias que compõem a área. Kepler passa então a relacionar áreas e tempos:

Portanto, a partir disso, como a área CDE está para a metade do tempo periódico, que designamos por $180^{\circ}$, assim também as áreas CAG, CAH estarão para o tempo percorrido sobre CG e CH. Assim, a área CGA torna-se uma medida de tempo ou anomalia mediana, correspondendo ao arco do excêntrico CG, visto que a anomalia mediana mede o tempo (Kepler, 1937 [1609], p. 265).

Kepler associa as áreas parciais percorridas com os tempos parciais percorridos, juntamente com a área total do semicírculo com o tempo para seu percurso, que fica assim:

Área CDE: Tempo Total (semicírculo):: áreas CAG, CAH: tempo CG, CH.

A anomalia mediana CGA, no caso do arco CG, é a medida de tempo para a computação do percurso dado pela área CGA (o mesmo valendo para as outras áreas). Em outras palavras, Kepler obteve que o planeta percorre áreas iguais em tempos iguais, computadas a partir do centro físico de movimentos, A, que representa o Sol. Aqui, já temos a formulação da segunda lei, mas Kepler não a reconhecia ainda como tal.

É importante lembrar que, neste ponto do relato, Kepler ainda se mantém no plano das questões relativas a uma astronomia descritiva, pois utiliza a parte ótica, o ângulo BGA, como o excesso que produz a anomalia mediana. Todas essas questões serão deixadas de lado quando Kepler reconhecer a sua hipótese das superfícies como uma lei dos movimentos planetários.

Toda a elaboração da hipótese das superfícies será, na quarta parte da Astronomia nova, de capital importância para a ruptura com a crença no axioma platônico, pois a hipótese das superfícies tem como fundamento a aceitação de um centro físico de movimento, o Sol, para uniformizar os tempos com as áreas percorridas. A impossibilidade de uma órbita circular adequar-se a essa relação levará Kepler, entre outros motivos, a rejeitar o princípio da circularidade exigida pelo axioma platônico dos movimentos planetários, como ele diz no início do capítulo 40 - escrito, provavelmente, quando já tinha obtido as suas duas primeiras leis, tendo definitivamente rompido, portanto, com a circularidade e a uniformidade. Nesse capítulo 4०, Kepler inicia seu trajeto para a obtenção da primeira lei afirmando:

Meu primeiro erro foi supor que o caminho do planeta é um círculo perfeito, uma suposição que era totalmente alicerçada na autoridade dos filósofos, mais 
convincente para a metafísica em particular. Em segundo lugar, admitir que o caminho do planeta era um excêntrico perfeito, pois na teoria do Sol a soma pela qual ele difere do caminho oval é imperceptível (Kepler, 1937 [1609], p. 263).

Os erros a que Kepler se refere impediram que ele reconhecesse a hipótese das superfícies, quando a formulou, como sendo uma lei, pois a admissão do axioma platônico impossibilitava outra trajetória que não a circular.

\subsection{O TESTE DO AXIOMA PLATÔNICO}

Determinada a hipótese das superfícies, Kepler passa a testar as hipóteses acerca da forma da órbita de Marte (cf. Tossato, 2003) tendo como instrumentos de trabalho os dados de Brahe, a hipótese vicária, a lei das distâncias e a hipótese das superfícies. Todo esse processo, contido na quarta parte da Astronomia nova, conduzirá à descoberta da primeira lei.

Primeiramente, Kepler testa a órbita circular, não encontrando correspondência entre ela e os dados de Brahe. $\mathrm{O}$ axioma platônico de movimentos circulares e uniformes torna-se a partir daqui uma hipótese. Kepler foi o primeiro astrônomo a pôr em dúvida esse princípio norteador da astronomia, submetendo-o ao teste da correspondência com as observações. A principal razão para isso é devida à impossibilidade de representar matematicamente a órbita circular quando consideramos o centro de movimentos não estando em um ponto geométrico fictício, mas em um corpo físico que, no caso do copernicanismo, é o Sol. O teste da circularidade e da uniformidade encontra-se nos capítulos 40 a 44 da Astronomia nova. Kepler nos diz, no capítulo 42, acerca dos resultados obtidos pelo teste da órbita circular:

Podeis ver, leitor, que devemos começar por um outro caminho. Pois podeis perceber que as três posições excêntricas de Marte e o mesmo número de distâncias do Sol, quando a lei do círculo foi aplicada a elas, rejeitaram o afélio encontrado acima (com uma pequena invariabilidade). Nisso está a fonte de nossa suposição de que o caminho do planeta não é um círculo. Sob essa suposição não é possível determinar as três distâncias em relação às outras. Portanto, a distância para qualquer lugar particular deve ser deduzida a partir de nossas próprias observações, especialmente aquelas no afélio e no periélio (Kepler, ${ }_{193}$ [1609], p. 275).

Dois pontos devem ser comentados na passagem acima. O primeiro é que as três posições a que se refere Kepler foram dadas por Brahe, com um grau de precisão jamais obtido até então. O segundo ponto refere-se à parte final, a de que devemos de- 
duzir a forma da órbita do planeta Marte pelas “nossas próprias observações”, isto é, negado o axioma platônico, devemos procurar elaborar hipóteses que correspondam às observações; devemos encontrar qual é a forma real da órbita de Marte sem qualquer princípio a priori que nos conduza nessa empreitada.

\section{$2.5 \mathrm{O}$ TESTE DA ÓRBITA OVAL}

Negada a órbita circular e livre das restrições impostas pelo axioma da circularidade, Kepler considera a forma oval mediante a investigação do movimento em epiciclo. Postulando a elipse auxiliar como forma da órbita, chega ao resultado de que a órbita circular erra por excesso, enquanto que a órbita oval (elipse auxiliar) erra por falta. Cabe lembrar que esta é a primeira utilização da forma elíptica por Kepler (cf. 1937 [1609], cap. 47). Mas, nesse estágio, ela era um instrumento de trabalho, para tentar representar uma órbita que Kepler já sabia não ser circular. O problema era o de determinar o tipo de oval e a elipse surge como um instrumento nessa determinação. A primeira lei, a forma elíptica real da trajetória planetária, só se dará no capítulo $5^{8}$, quando Kepler consegue representar satisfatoriamente os movimentos pela elipse e, principalmente, quando a elipse se mostrar como uma representação que corresponde aos movimentos observados de libração (oscilação), que Kepler tentará explicar pelo conceito de força magnética.

A primeira utilização da elipse por parte de Kepler ocorre no seio de uma série de cálculos, nos quais Kepler obtém o resultado que entre o excêntrico e a órbita oval de Marte existe uma pequena área, chamada por ele de lúnula, a qual é calculada como tendo um valor igual a $85^{8}$ unidades, quando o raio da órbita tem o valor de 100.000 unidades. Kepler nota que em direção ao afélio a figura oval apresenta-se mais larga, e em direção ao periélio ela se apresenta mais estreita (cf. Kepler, 1937 [1609], cap. 47). O problema do astrônomo era, agora, representar essa figura oval de modo que desse conta das irregularidades observadas entre o afélio e o periélio de Marte. É na tentativa de resolver esse problema que Kepler emprega a elipse como um expediente geométrico de aproximação.

No capítulo 47, a elipse não tem ainda a função de representar, sob o ponto de vista realista, a forma da órbita de Marte. Ela se liga à tentativa de compreensão da forma oval, que se explica pelo motivo de que a oval não é uma curva estritamente geométrica, que obedeça a parâmetros de construção geométrica, como se pode fazer com o círculo, a elipse, a hipérbole ou a parábola. 


\subsection{A OBTENÇÃo DA PRIMEIRA LEI}

Nos capítulos $5^{\circ}$ a 55 da Astronomia nova, Kepler esforça-se para alcançar seus objetivos. Esses capítulos apresentam uma série de fracassos; porém Kepler obtém alguns resultados que serão de grande importância no desenvolvimento da Astronomia nova. Um dos mais relevantes é a descoberta de que a largura da lúnula obtida com o valor de $85^{8}$, mediante a elipse auxiliar, apresentava-se muito larga, ela é, por isso, dividida. Kepler utiliza 22 observações diferentes de Brahe e confirma o resultado de que a largura da lúnula, aplicada mediante a elipse auxiliar, deve ser de 432 (cf. Kepler, 1937 [1609], cap. 53); na realidade o valor é de 429, mas Kepler despreza essa pequena diferença. Com isso, ele percebe que o valor obtido é muito pequeno, quando comparado às observações de Brahe, considerando, consequentemente, que a utilização da órbita oval leva a negar a órbita circular, mas que, principalmente, ainda não obtém uma representação satisfatória para a órbita de Marte por meio da hipótese da trajetória oval.

Assim, nos capítulos 54 e 55, Kepler considera que, dados os resultados alcançados até agora, as distâncias calculadas pela hipótese circular tornam-se muito grandes, isto é, erram por excesso, quando comparadas aos dados de Brahe; em contrapartida, as distâncias calculadas pela hipótese oval, mediante a elipse auxiliar, erram por falta, por serem muito pequenas (cf. Kepler, ${ }_{19} 37$ [1609], p. 345).

Todo o processo que envolve a parte final da obtenção da primeira lei de Kepler é algo que escapa aos domínios deste artigo. ${ }^{10}$ Sigamos um resumo de Koyré para o procedimento dado por Kepler para a obtenção da primeira lei dos movimentos dos planetas. Pela figura abaixo, Koyré escreve que:

Para determinar a posição de Marte em relação ao Sol, Kepler começa traçando a linha das apsides e o círculo excêntrico que Marte teria percorrido, se sua órbita fosse circular (mas que, de fato, ele não percorre); nesse caso, Marte, encontrando-se em um momento dado no ponto M, estaria à distância MS do Sol. Ora, sabemos que isso não é o caso, e que essas distâncias devem ser encurtadas e diminuídas pelo valor da oscilação efetuada pelo planeta sobre o diâmetro de seu

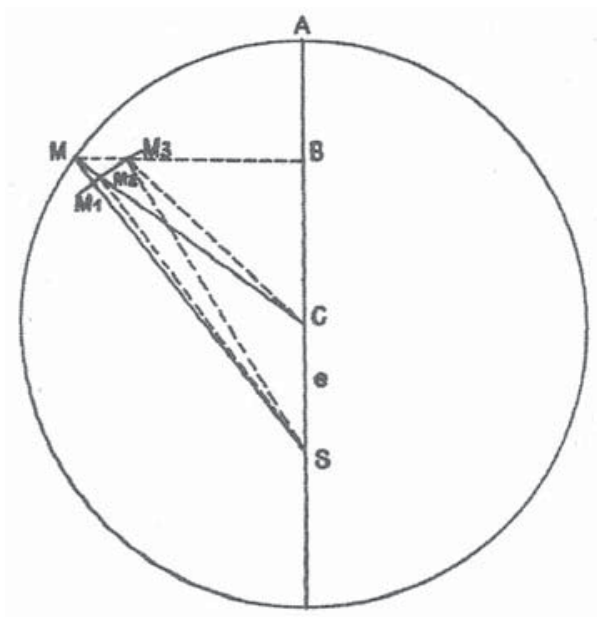

10 A prova de que as órbitas são elípticas contém uma riqueza de detalhes e de demonstrações geométricas. O capítulo 59 da Astronomia nova que apresenta a prova contém 15 proposições voltadas para a prova geométrica de que a elipse é a forma do movimento de Marte e dos outros planetas (cf. Koyré, 1961; Tossato, 1997). Também é importante ressaltar que a hipótese das superfícies adquire o estatuto de lei na proposição 15 do capítulo 59 . 
epicíclo (fictício) (...) Ele estará, portanto, na distância SM (e não na distância SM) do Sol. Ora, entretanto, onde se encontra Marte? Kepler estima que ele deve demorar-se sobre o raio do círculo excêntrico (CM), portanto, no ponto $M_{2}$, de modo que $\mathrm{SM}_{1}=\mathrm{SM}_{2}$.

As observações não confirmaram seu raciocínio, Marte se encontraria no ponto $\mathrm{M}_{3}$, à direita da posição calculada (...) não se tem nenhuma razão para afirmar que o planeta se encontraria sobre o raio (fictício) do círculo excêntrico que ele não percorre (Koyré, 1961, p. 262-3).

Porém, faltava relacionar essa curva elíptica com a libração do planeta. Kepler percebeu que a órbita elíptica pode ser produzida pela teoria da libração, se o planeta não estiver localizado sobre o raio do excêntrico, mas sobre a perpendicular a partir da posição sobre o excêntrico na linha das apsides, o que levou Kepler a afirmar que "eu pensava que a oscilação sobre o diâmetro não poderia ser gerada pela elipse. Foi como uma pequena revelação para mim, quando percebi que a oscilação pode gerar uma elipse" (1937 [1609], p. 366).

Desse modo, Kepler obtém a sua primeira lei. O movimento de libração do planeta ao longo de seu trajeto mostra que o planeta tem um movimento elíptico e esse movimento está em correspondência com as posições observadas (dados de Brahe) do planeta Marte e, além disso, determina as distâncias de Marte ao Sol.

Kepler conclui que a verdadeira forma da órbita de Marte está a meio caminho entre o círculo e a elipse auxiliar. Com isso, percebe-se o papel desempenhado nas pesquisas astronômicas pela interpretação realista dada às hipóteses astronômicas vcisando a descrição e a explicação do comportamento observado dos planetas ao longo de seus trajetos no céu.

\subsection{ForÇA}

Mas a questão que pôs Kepler para si mesmo é: o que move os planetas? Tal pergunta é necessária, pois Kepler não está mais no plano meramente da representação matemática (descritivo) dos movimentos, mas trabalha, agora, no plano da explicação, do que efetivamente acontece. Kepler adota o copernicanismo e admite que os movimentos devem ser computados em função do centro físico dos movimentos, que é o Sol real e não um ponto matemático fictício. Como vimos, isto conduz à recusa da circularidade e da uniformidade, ao abandono do chamado axioma platônico. Se a órbita não é circular, mas elíptica, o que faz o planeta percorrer uma tal trajetória? É evidente como opera a explicação causal de Kepler. Parte da hipótese de que as forças magnéticas do Sol são a causa eficiente do movimento dos planetas, permitindo explicar precisamente os 
efeitos observados, ou seja, as desigualdades observadas dos movimentos planetários. Entretanto, os efeitos observados são explicados por uma causa física (a ação magnética do Sol) inobservável.

A tentativa de resposta de Kepler está assentada em seu conceito de força. É uma força magnética exercida pelo Sol nos planetas que faz com que eles percorram velocidades e tempos proporcionais de acordo com o aumento ou a diminuição das suas distâncias ao Sol. Kepler utiliza o magnetismo, muito conhecido e investigado em sua época. A filosofia (hipótese) magnética foi formulada principalmente por William Gilbert (1540-1603), em seu famoso De magneto. Kepler utiliza o magnetismo por intermédio de uma analogia posta para aproximar-se da explicação de como o Sol age sobre os planetas. A analogia refere-se a um barco no meio da ação de correntezas que produzem movimentos em turbilhão, redemoinhos: o barco, com um remador em seu interior, sofre a ação do centro do redemoinho, que o atrai; o remador, por sua vez, procurará conduzir o barco para fora da ação do redemoinho; a analogia está em que o Sol é o centro do redemoinho, e os planetas representam o barco (cf. Kepler, 1937 [1609], p. 349). Kepler considera falha essa analogia, pois a ação do rio é material, ou melhor, observável, enquanto que a ação do Sol nos planetas, apesar de natural e física, é inobservável (cf. p. 349-50). Assim, a ação do Sol, a força exercida por ele nos planetas, que tem como efeito os movimentos dos mesmos, é um inobservável, tal como o é a ação do magneto. Segundo o próprio Gilbert:

A união de corpos que estão separados um do outro, e que são naturalmente parecidos, atraem-se por um outro grupo de movimentos, se eles forem livres para moverem-se. A terrela envia sua força para fora em todas as direções, segundo a sua energia e qualidade. Mas se o ferro ou outro corpo magnético de tamanho apropriado cair sob sua esfera de influência, ele será atraído; com efeito, quanto mais próximo estiver do imã, maior será a força com a qual é atraído para ele. Tais corpos tendem para o imã, não como para um centro, nem para o seu centro: eles apenas o fazem como seus polos, isto é, quando aquilo que é atraído e o polo do imã, assim como seu centro, estão em linha reta. (...) Nos polos a linha é reta. Quanto mais próximo forem as partes do círculo equinocial, maior obliquidade da atração dos corpos magnéticos, mas as partes mais próximas dos polos atraem mais diretamente; nos próprios polos, a atração se dá em linha reta. Todo imã semelhante, seja esférico ou oblongo, tem o mesmo modo de voltar-se para os polos do mundo; mas isso é mais fácil de experimentar com os oblongos (...). Assim, o imã e a Terra se conformam com os movimentos magnéticos (Gilbert, $195^{8}$ [1600], p. 121-2). 
Para Gilbert, as forças magnéticas têm uma maior intensidade nos polos, sendo que elas diminuem nas partes equatoriais. Kepler utiliza o que Gilbert fez para os imãs e para a própria Terra, nos movimentos dos planetas (cf. Kepler, ${ }_{1937}$ [1609], p. 350). Note-se que Kepler utilizará a hipótese magnética de Gilbert, segundo a qual a Terra é um enorme magneto, para afirmar que também o Sol é um grande magneto, que atrai a Terra e os planetas, de modo que há uma variação na intensidade da ação. Kepler adiciona a variação nas distâncias, o que lhe permite postular que a ação do Sol diminui conforme as distâncias aumentam, e essa ação se fortalece quando as distâncias diminuem, gerando uma velocidade maior e um tempo menor quando o planeta está próximo ao Sol (pois este o está mais intensamente atraindo), e uma velocidade menor e tempo maior quando o planeta está mais afastado do Sol (pois o planeta sofre uma ação menos intensa da força magnética do Sol). Isso traz a questão para as forças naturais, pois como Kepler mesmo escreve:

Finalmente, em nenhum desses casos vistos, a mente, através de suas faculdades animais, as quais agiriam sobre a constante direção do eixo magnético, tem a condição de inclinar o eixo na continuação dos séculos. Mas se em nenhum desses casos isso ocorre, nem mesmo a idéia geral de mente pode ocorrer, então contentemo-nos com a natureza, a qual está em conformidade com todos os outros efeitos (Kepler, 1937 [1609], p. 364).

O raciocínio de Kepler é que, como é possível encontrar uma proporcionalidade para as relações dos movimentos planetários, é possível determinar racionalmente uma causa natural. Kepler afasta-se, assim, das hipóteses animistas, tais como o recurso a inteligências planetárias ou faculdades animais e outros termos semelhantes.

\section{O GARÁTER EXPLICATIVO DAS HIPÓTESES ASTRONÔMICAS}

A partir da apresentação do processo de elaboração kepleriano para as duas primeiras leis dos movimentos planetários, algumas perguntas podem ser sugeridas. Em primeiro lugar, que tipo de concepção de ciência está subjacente a esse processo? Que estatuto Kepler dá para os elementos de que ele dispunha; ou seja, qual é o papel das observações, das hipóteses de trabalho, das concepções teóricas e das teses axiológicas e metafísicas por ele aceitas? Finalmente, como ele trata metodologicamente todos esses elementos?

Como resposta a essas questões, apresentamos as principais teses envolvidas no trabalho de obtenção das duas primeiras leis dos movimentos dos planetas. Podemos 
listar, a partir dos resultados dados na segunda seção deste artigo, as "ferramentas" utilizadas por Kepler nesse processo de elaboração de suas leis:

(1) Em primeiro lugar, está a aceitação das hipóteses copernicanas de centralidade do Sol e de movimento da Terra;

(2) a seguir, temos o uso dos dados observacionais de Brahe, que serviram como base para o teste de hipóteses;

(3) o método kepleriano, que se concentra nos seguintes aspectos: (a) estipulação de hipóteses de caráter físico, isto é, que não sejam apenas hipóteses no sentido instrumentalista (artifícios para adequar os dados ao axioma platônico), mas que remetam às características físicas e dinâmicas presentes nos movimentos dos planetas, bem como o teste das hipóteses sobre a verdadeira forma das órbitas planetárias; (b) utilização de analogias como modo de dar plausibilidade à hipótese física da centralidade do Sol, sendo a mais importante o uso da força magnética, proposta anteriormente por Gilbert, para postular a ação da força exercida pelo Sol nos planetas;

(4) uso dos artifícios geométricos (apenas durante o processo de obtenção das leis, isto é, como recursos que foram importantes para a aproximação com o modelo final de astronomia física), tais como o equante, o epiciclo, o deferente etc.;

(5) estipulação de hipóteses de trabalho (hipóteses auxiliares): hipótese vicária, lei das distâncias; hipótese das superfícies e elipse auxiliar;

(6) aceitação de que a astronomia pode considerar os aspectos físicos e dinâmicos envolvidos.

Um exame atento desses aspectos mostra-nos o modo kepleriano de construir a ciência e conduz-nos a pensar algumas coisas. Inicialmente, podemos caracterizar a explicação de Kepler alicerçada nas seguintes teses:

(1) os movimentos planetários são causados pela ação de uma força magnética central;

(2) a causalidade se resume à causa eficiente;

(3) o universo físico é racional (isto é, o mundo físico - distintamente do platonismo - é objeto de pesquisa, pois não se deve vê-lo como objeto que transcende a capacidade humana de compreensão);

(4) a astronomia deve ser tanto explicativa quanto preditiva;

(5) o universo deve ser interpretado realisticamente. 
A partir disso, as principais teses epistemológicas keplerianas são:

(1) as faculdades cognitivas humanas (a razão natural) podem compreender e expressar o mundo celeste, seja sob o ponto de vista físico (explicação), seja sob o ponto de vista matemático (descrição);

(2) a experiência é básica para a obtenção do conhecimento, pois os dados observacionais são uma parte, uma expressão, da estrutura real do universo; contudo, devem ser entendidos mediante a análise conceitual das regularidades operada pela razão;

E, finalmente, temos a seguinte tese metodológica:

(1) visto que o intelecto e a experiência mantêm uma relação (isto é, o conhecimento é um conjunto composto pela parte empírica, que determina os dados, e esses devem ser entendidos pelo intelecto), os meios para obter conhecimento devem ser o de formulação de hipóteses, as quais têm um estatuto realista e não instumentalista, ou seja, são hipóteses acerca das causas físicas dos movimentos.

Assim, chegamos ao ponto principal deste artigo: o método kepleriano para a astronomia alicerça-se no processo de elaboração de hipóteses. Kepler sempre teve como meta a descrição da realidade do mundo celeste, e a ordenação copernicana é o sistema que expressa essa realidade; porém, o seu realismo não é de cunho apriorista, mas o conhecimento constrói-se de acordo com as informações que as observações determinam. Acerca do estatuto das hipóteses astronômicas, Kepler comenta o prefácio do Derevolutionibus de Copérnico, prefácio escrito, como mostrou Kepler, por Osiander:

Eu conheço a opinião de que as hipóteses não são artigos sobre os fatos, mas bases para cálculos, de maneira que, mesmo que elas forem falsas, não se deve rejeitá-las, desde que elas concordem com os movimentos aparentes.(...) Parece-me que nessas palavras do autor ocorre um claro equívoco sobre a palavra "hipótese”. Pois, algumas hipóteses descritas acima são, assim falando, pequenas alterações, sendo errado considerá-las como hipóteses, sendo que outras são verdadeiramente hipóteses astronômicas. Assim, quando no exemplo de Osiander, nos determinamos e relatamos a parte do círculo planetário a qual está ligada à metade do círculo do zodíaco, é errado considerá-la como hipótese e ela não pode ser verdadeira ou falsa. Mas, quando procuramos um método para calcular a ascensão ou descensão de um planeta nas partes desiguais, podemos chegar a isso 
de várias formas e, assim, construímos hipóteses com o propósito de determinar o que é primeiro: uns localizando o centro do círculo no centro do mundo, outros colocando um epiciclo em um concêntrico. Mas essas, de fato, não são hipóteses astronômicas, mas, sim, geométricas. Portanto, se algum astrônomo diz que o caminho [órbita] da Lua tem uma forma oval, temos uma hipótese astronômica. Mas, por outro lado, quando ele procura construir essa forma através de círculos, ele está se utilizando de hipóteses geométricas (...). Nenhuma dessas coisas [a opinião de Osiander] pode ser tomada seriamente quando nós conhecemos a natureza e diversidade das hipóteses (Kepler apud Jardine, 1979, p. 164,-5).

As hipóteses astronômicas não são geométricas, mas físicas (cf. Tossato, 2008). Isso fica claro quando recorremos ao processo de obtenção das leis descrito na segunda seção deste artigo. Kepler, após ter obtido a segunda lei, não utiliza a circularidade e a uniformidade como um axioma, mas toma essas qualidades como uma suposição e as nega quando as predições dos movimentos dos planetas, feitas a partir da circularidade e uniformidade, não concordam com a pequena margem de erros dos dados de Tycho Brahe. Isto é, o processo é hipotético e o caráter da hipótese vai depender do objetivo a que serve essa hipótese. Assim a hipótese é matemática quando o objetivo é simplesmente calculatório ou representacional (descritivo) e a hipótese é física quando o objetivo é explicativo. As hipóteses físicas na astronomia, Kepler denomina hipóteses astronômicas.

\section{Conclusão}

Este texto procurou mostrar que um dos pontos mais importantes da astronomia kepleriana está na elaboração de uma nova perspectiva de tratamento dos movimentos planetários. Kepler pensa a astronomia como matemática e explicativa, como uma disciplina na qual as hipóteses astronômicas não podem ser entendidas como propiciando somente uma descrição dos movimentos dos planetas, mas devem dar conta de por que os planetas percorrem uma órbita elíptica (primeira lei) e, também, por que apresentam as proporções observadas entre as áreas e os tempos (segunda lei). Sua defesa do copernicanismo é, assim, claramente realista. A ruptura com o compromisso metodológico da equivalência das hipóteses astronômicas, imposto pelo axioma platônico, representou para Kepler a possibilidade de tomada de decisão entre as hipóteses de Ptolomeu, Brahe e Copérnico. Os dois primeiros, ao posicionarem a Terra no centro dos movimentos planetários, enfraquecem o caráter explicativo de suas hipóteses, pois a hipótese da Terra estacionária não possibilita explicar, por exemplo, o movimento 
retrógrado dos planetas, que, entretanto, recebe uma explicação plausível pela hipótese copernicana da mobilidade da Terra. Kepler, desde o início, assumiu a hipótese copernicana da centralidade física do Sol, como restrição à qual os dados observacionais deveriam estar adequados. E essa hipótese física serviu como guia na descoberta das duas primeiras leis dos movimentos planetários.

Agradecimentos. A elaboração deste artigo teve o apoio da Fapesp com a concessão de uma bolsa de Pós-doutorado a Claudemir Roque Tossato. Agradecemos a Valter Alnis Bezerra por suas valiosas sugestões para este artigo.

\title{
Claudemir Roque Tossato
}

Professor de Filosofia da Ciência,

Universidade Federal de São Paulo, Brasil.

toclare@uol.com.br

\section{Pablo Rubén Mariconda}

Professor Titular de Teoria do Conhecimento e Filosofia da Ciência, Departamento de Filosofia, Universidade de São Paulo, Brasil.

ariconda@usp.br

\begin{abstract}
This article deals with the methodological procedures employed by Johannes Kepler, particularly those used in the process of elaboration of the two first laws of planetary movements. Its aim is to show that the astronomical practice of Kepler is linked with the proposal of (physical and mathematical) hypothesis and with valuing precision in observational data, with the goal of obtaining, by means of rigorous procedures, the (mathematically expressed) regularities of planetary motions. It was only afterwards that Kepler looked for an explanation of the regularities (laws) discovered, formulating the hypothesis of the magnetic action exerted by the Sun, which is located at the physical center of the system. In the Astronomia nova, he modifies the methodological status of astronomical hypotheses in the beginning of $17^{\text {th }}$ century (present in Ptolemy, Copernicus and Brahe), promoting the passage from a mathematical descriptive astronomy to a physical-mathematical explicative astronomy.
\end{abstract}

KEYwords • Kepler. Method. Astronomical hypothesis. Laws of planetary motions. Astronomical observations. 


\section{O método da Astronomia SEgundo Kepler}

\section{REFERÊNGIAS BIBLIOGRÁFIGAS}

Aтton, E. J. Kepler's second law of planetary motion. Isis, 205, p. 75-90, 1969.

Infinitesimals and the area law. Vistas in Astronomy, 18, p. $5^{8} 5^{-6}, 1975$.

Kepler's path to the construction and rejection of his first oval orbit for Mars. Annals of Science, 39 , p. $17^{3-90,1978 . ~}$

Caspar, M. Kepler. New York: Dover Publications, 1959.

Caspar, M. \& von Dick, W. (Ed.). Gesammelte Werke. Munich: C. H. Beck'sche Verlagsbuchhandlung, 1937$1975 \cdot 23 \mathrm{v}$.

Dreyer, J. L. E. A history of astronomy from Thales to Kepler. New York: Dover Publications, $195^{3}$.

Euclides. The thirteen books of the elements. Tradução T. L. Heath. New York: Dover Publications, 1956. 3 v. Gilbert, W. On the loadstone and magnetic bodies. New York: Dover Publications, $195^{8}$ [1600].

JaRDInE, N. The forging of modern realism: Clavius and Kepler against the sceptics. Studies in History and Philosophy of Science, 10, 2, p. 14,1-73, 1979.

Kepler, J. Astronomia nova. In: Caspar, M. \& von Dick, W. (Ed.). Gesammelte Werke. Munich: C. H. Beck'sche Verlagsbuchhandlung, ${ }_{1937}^{3}$ [1609].v. 3.

. Mysterium cosmographicum, In: Caspar, M. \& von Dick, W. (Ed.). Gesammelte Werke. Munich: C.

H. Beck'sche Verlagsbuchhandlung, 1938 [1596]. v. 1, p. 1-80.

Koyré, A. La révolution astronomique. Paris: Hermann, 1961.

Lorenzano, P. \& Miguel, H. (Ed.). Filosofia e historia de la ciencia en el cono sur. Buenos Aires: Editorial CCG Educando, 2008.

Martens, R. Kepler's philosophy and the new astronomy. Princeton: Princeton University Press, 2000.

Simon, G. Kepler, astronome astrologue. Paris: Gallimard, 1979.

Small, R.An account of the astronomical discoveries of Kepler. Madison: The University of Wisconsin Press, 1963.

Stephenson, B. Kepler's physical astronomy. New York: Springer Verlag, 1987.

Tossato, C. R. O processo de elaboração das duas primeiras leis keplerianas dos movimentos planetários. São Paulo, 1997. Dissertação (Mestrado em Filosofia). Faculdade de Filosofia, Letras e Ciências Humanas, Universidade de São Paulo.

. Os primórdios da primeira lei dos movimentos planetários na carta de 14/12/1604, de Kepler a Mästlin. Scientiae Studia, 1, 2, p. 195-206, 2003.

. Discussão cosmológica e renovação metodológica na carta de 09/12/1599 de Brahe a Kepler. Scientiae Studia, 2, 4, p. 537-65, 2004.

. O realismo kepleriano das hipóteses astronômicas. In: Lonenzano, P. \& Miguel, H. (Ed.). Filosofia e historia de la ciencia en el cono sur. Buenos Aires: Editorial CCC Educando, 2008. p. 525-33.

Voelkel, J. R. The composition of Kepler's “Astronomia nova”. Princeton: Princeton University Press, 2001.

Wilson, C. Kepler's derivation of elliptical path. Isis, 59, p. 5-25, 1968.

How did Kepler discover his first two laws? Scientific American, 226, p. 92-106, 1972.

Kepler's ellipse and area rule - their derivation from fact and conjecture. Vistas in Astronomy, 18 , p. $5^{8} 7^{-91}, 1975$. 


\section{GLOSSÁRIO ASTRONÔMICO}

A seguir, são apresentados alguns dos termos mais importantes dentro do processo de obtenção das duas primeiras leis dos movimentos planetários, tal como exposto neste artigo.

Anomalia (Excêntrica e Verdadeira): Ângulos que permitiam calcular as posições de um astro em movimento em função dos pontos característicos da linha das apsides. Na figura 3, A é o Sol, B é a excentricidade e G é um planeta; o ângulo CBG é a anomalia excêntrica e o ângulo GAC é a anomalia verdadeira.

Anomalia mediana: É uma antiga medida de tempo que determina o ângulo formado pelo trajeto do corpo planetário ao longo do círculo excêntrico; isto é, um ângulo formado pela posição do planeta em relação à linha das apsides e ao centro do sistema. Na figura 3, a anomalia mediana é o ângulo AGB.

Apsides, Linha das: Linha que contém os pontos mais extremos das órbitas. Na figura 3, CD é a linha das apsides.

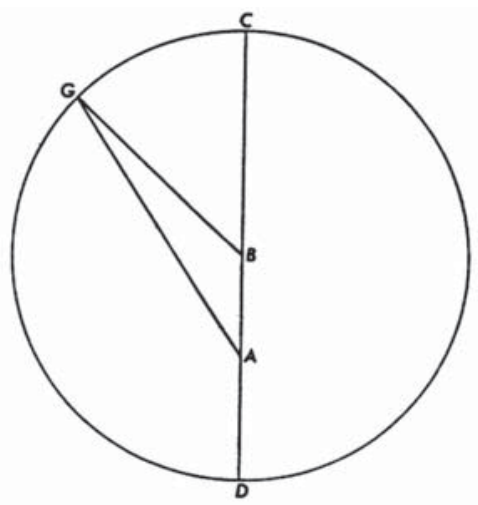

Figura 3

Equante (ou Punctum aequans): objetivava determinar ângulos iguais em tempos iguais, isto é, o planeta realizaria um movimento uniforme não mais sobre o centro do deferente, ou sobre o centro do círculo excêntrico, mas sobre o equante. Na figura 4, O é a Terra, C o centro do deferente, E o equante. A é o apogeu, II é o perigeu, K é o centro do epiciclo, P é um planeta. P perfaz um movimento uniforme e circular, salvando conjuntamente a primeira e a segunda desigualdades fazendo movimentos epicíclicos, tendo como centro do movimento o ponto E, que é um ponto fictício (geométrico). Desta forma, tendo E como centro, o planeta move-se com velocidade angular constante. 


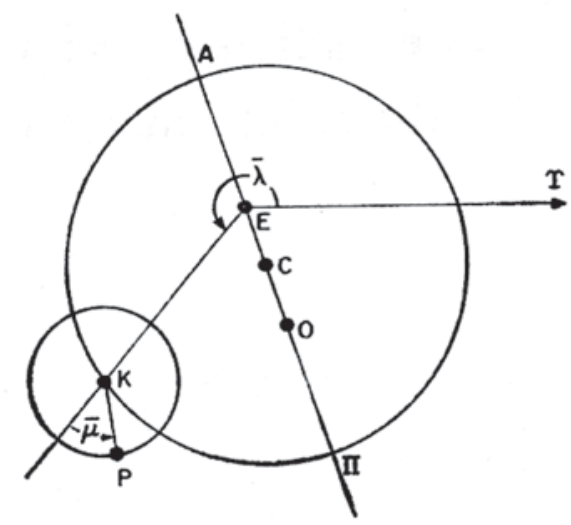

Figura 4

Epiciclo com Deferente: Artifícios matemáticos destinados a explicar as irregularidades dos movimentos planetários. O planeta realiza movimento circular ao longo do epiciclo, cujo centro realiza movimento circular sobre o círculo deferente, o qual contém o centro dos movimentos. Por esse mecanismo, pode-se representar todas as irregularidades e ajustá-las ao axioma platônico (cf. figura 5 ).

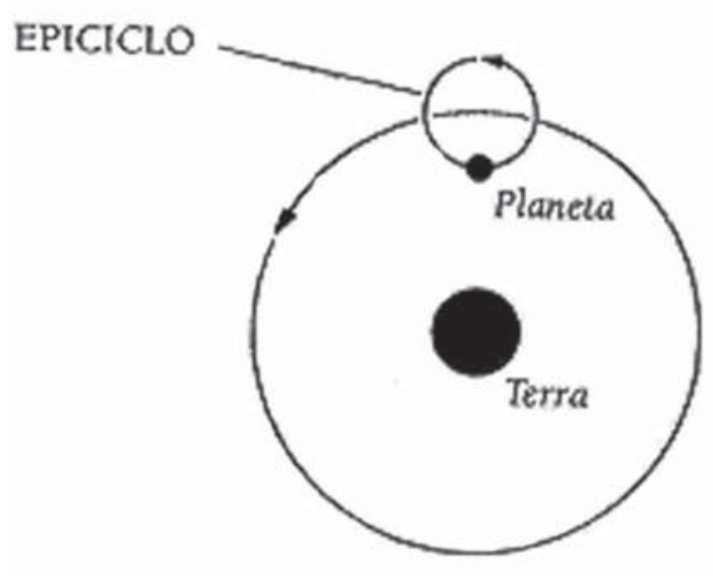

Figura 5

Excentricidade: Distância entre o centro físico de movimentos e o ponto em que é medida a circularidade e uniformidade. Na figura 3, é a distância AB.

Excentricidade bissectada: Excêntrico que contém um equante.

Latitude: Coordenada eclíptica de um ponto da esfera celeste; distância angular desse ponto à eclíptica.

Longitudes heliocêntricas: pontos (posições) dos planetas durante o seu percurso ao redor do Sol. 
Oposição: Ocorre quando dois corpos celestes estão a $180^{\circ}$ um do outro, vistos da Terra, por exemplo, Marte está em oposição ao Sol quando entre eles está a Terra.

Primeira desigualdade (ou primeira irregularidade): Irregularidade constatada observacionalmente, que mostra a inconstância dos períodos nos percursos dos corpos celestes. Por exemplo, a variação na intensidade de luz de um planeta, a inconstância nos períodos das estações etc. A primeira desigualdade expressa a não uniformidade dos movimentos dos planetas.

Quadrante: $O$ círculo excêntrico é dividido em quatro partes, a partir da excentricidade, cada parte é um quadrante. Quando se divide em oito partes, cada parte chamase Octante.

Segunda desigualdade (ou segunda irregularidade; movimento retrógrado): Irregularidade constatada observacionalmente, que mostra as inconstâncias nas trajetórias dos corpos celestes, isto é, os movimentos de retrogradação dos planetas. A segunda irregularidade expressa a não circularidade dos movimentos planetários.

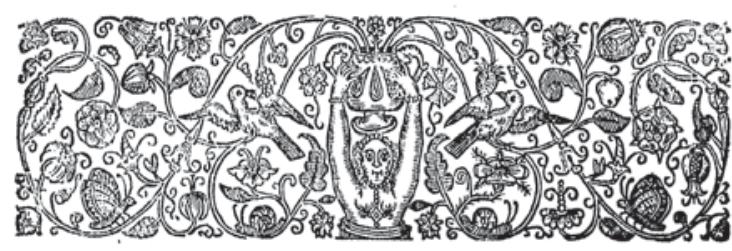

